\section{Acalculous Cholecystitis}

The great majority of patients with disease of the gall bladder have stones in it, yet there is no doubt that acalculous cholecystitis, though unusual, does exist. In practice the conditions found at operation may range from a perfectly normal gall bladder removed because of suspected biliary disease, through gall bladders with mild histological changes in the wall, to undoubted examples of acute, indeed even gangrenous, cholecystitis in the absence of stones.

For some time the poor prognosis of patients submitted to cholecystectomy despite the absence of gross lesions in the gall bladder and with a cholecystogram that was only questionably abnormal cast doubt on whether a definite disease entity was being diagnosed. Thus W. A. Mackey, in a review of 243 such patients, ${ }^{1}$ found over one-third had a poor functional result. He concluded that cholecystitis without stone "seems to belong to a region on the border line between functional and organic disease."

More recently F. Glenn and H. Mannix ${ }^{2}$ studied a group of 135 patients who had neither stone nor acute inflammation; these patients were in a series of 3,110 undergoing cholecystectomy. The results were somewhat unhappy ; 22 had severe postoperative complications $(16.3 \%)$ and there were three deaths. Of 121 of the patients followed up, a quarter had no relief from their original symptoms. Careful microscopical examination of the excised specimens showed no difference between those cases with good results and those with no improvement, so that these authors state, "One may well question the actual role of cholecystectomy in the clinical improvement."

Yet undoubtedly acute cholecystitis, even progressing to frank gangrene and perforation, can occur in the absence of a stone. S. O. Hoerr and J. B. Hazard, ${ }^{3}$ in reviewing 14 such cases, define four possible causes. There may be noncalculous obstruction of the cystic duct from fibrosis, kinks, or twists, or from an anomalous cystic artery or tumour. There may be infarction of the wall of the gall bladder due to arteriosclerosis or embolism. There may be reflux of pancreatic juice, producing a chemical cholecystitis. Or there may be bacterial invasion of the gall bladder wall. Typhoid cholecystitis is a good example of the last group.

An interesting review of the whole subject of acalculous cholecystitis has recently come from A. M. Munster and J. R. Brown, ${ }^{4}$ of the Peter Bent Brigham Hospital, Boston. Out of 541 cholecystectomies 12 cases of acalculous cholecystitis were found $(2.2 \%)$. There were four examples of acute cholecystitis, three more showed undoubted active chronic disease, and the remaining five had only minimal evidence of mild chronic cholecystitis. Not unexpectedly the patients with acute acalculous cholecystitis did well after surgical operation, whereas of the five with minimal disease two had persistent symptoms and one has been lost to followup.

The situation can be summed up as follows. If a patient has typical symptoms and signs of gall-bladder disease in the absence of radiological evidence of stone and with normal appearances on barium-meal examination of the upper gastrointestinal tract, the surgeon may still find himself forced to perform a laparotomy. He may detect some unsuspected lesion-for example, chronic pancreatic disease.

' Mackey, W. A., Brit. 7. Surg., 1934, 22, 274.

2 Glenn, F., and Mannix, H., Ann. Surg., 1956, 144, 670.

? Hoerr, S. O., and Hazard, J. B., Amer. 3 Surg, 1966, 111, 47

Munster, A. M., and Brown, J. R., ibid., 1967, 113, 730 .
He may find tiny stones in the gall bladder which were undetected on $x$-ray examination, or there may be evidence of acalculous cholecystitis with gross thickening and inflammation of the wall of the gall bladder, adhesions to adjacent viscera, and other signs of disease. In these circumstances cholecystectomy will probably relieve the patient's symptoms. If the gall bladder appears normal, if the aspirated bile is clear, and if stones can still not be felt when the organ has been completely emptied, cholecystectomy is unlikely to be of value and will merely add to the possible risk of the exploratory operation.

\section{Novelty at Nottingham}

The creation of a complete new medical school at Nottingham presents the opportunity for putting into practice many of the imaginative ideas discussed at three world conferences on medical education and innumerable smaller gatherings since the war. It is therefore refreshing to see that a report ${ }^{1}$ published this week offering recommendations for the administration of the teaching hospital contains an entirely novel proposal. This concerns the relationship between the teaching hospital, Nottingham University, and Sheffield Regional Hospital Board.

The central problem for a large undergraduate teaching hospital is to reconcile the need to provide comprehensive medical care to the population among whom it is set with the obligation to teach. In addition, it must offer facilities that will allow and even encourage research. For a variety of reasons England and Wales took a different path from Scotland when the National Health Service was introduced, and arrangements in Northern Ireland are again slightly different. Despite some criticisms over the years it cannot be said that there is any great dissatisfaction either with the separation of boards of governors of teaching groups from regional hospital boards in England and Wales or with the co-ordination of their functions under single boards beyond the Border. But when the local joint committee of Sheffield Regional Hospital Board and Nottingham University came to look at the problem it faced plans which, as its report says, are "without precedent or parallel in the United Kingdom." And these words too are a refreshing token of the Nottingham planners' disinclination, evident in the report, to follow precedent or trot along parallel lines.

If the new teaching hospital was placed under the existing regional hospital board it would have the disadvantage of being controlled by a body 40 miles away and separated by congested lines of communication. It is a body, too, which in England and Wales has no statutory responsibility to provide the university with facilities for teaching. Yet the setting up of new and elaborate hospital services for a large population can be done satisfactorily only in the closest cooperation with the existing regional board. This consideration, combined with the difficulties of communication that would hamper a separate board in Nottingham have weighed against the establishment of a new board of governors.

What the joint committee therefore recommends is a governing body-" University Hospital Board of Manage-

Sheffield Regional Hospital Board and the University of Nottingham, Report on the Form of Government for the Teaching Hospital at Notingham, 1967. 2s. net. Obtainable from Secretary to Sheffield Regional Hospital Board, Fulwood House, Old Fulwood Road, Sheffield S10 3TH. 